\title{
ESTIMATION OF THE SIZE OF THE PATENT DUCTUS ARTERIOSUS FROM HEMODYNAMIC DATA
}

\author{
By NOBLE O. FOWLER ${ }^{1}$ AND EDGAR P. MANNIX \\ (From the Departments of Medicine and Surgery, State University of New York at New York \\ City, and the Cardiac Laboratory, Brooklyn Hospital, N. Y.)
}

(Submitted for publication December 13, 1954; accepted March 30, 1955)

The effects of patent ductus arteriosus upon the circulation were studied by Eppinger, Burwell, and Gross (1). Later, Dexter, Haynes, Burwell, Eppinger, Sosman, and Evans (2) described preoperative and postoperative hemodynamic studies obtained by cardiac catheterization in a patient with patent ductus arteriosus. Since the presence of a patent ductus arteriosus can. be detected by physical examination in more than 95 per cent of the patients having this condition (3), cardiac catheterization studies are needed as an aid to diagnosis only where the murmur is atypical, or when there is a possibility of an additional abnormality. When the single lumen cardiac catheter is used, it may be very difficult to distinguish between shunts of oxygenated blood into the upper right ventricle and shunts into the pulmonary artery (4). At times, aortography may be needed to settle the diagnosis unless the cardiac catheter is passed through the ductus arteriosus.

Hemodynamic data may, however, be of assistance in estimating the size of the patent ductus arteriosus (5). This information may be of value in contemplating interruption of the ductus in very young children, or in adults over the age of forty. In addition, the suggestion of a very large channel may warn the surgeon of possible technical difficulties in its ligation or division.

This paper describes in twelve patients a comparison between the diameter of the ductus as measured at operation and certain hemodynamic observations obtained preoperatively. In the preoperative study, the following values were determined: increase in oxygenation of pulmonary arterial over mixed venous blood; volume of left to right shunt through the ductus; the internal diameter of the ductus arteriosus calculated from an orifice formula (5).

\footnotetext{
1 Present address: Department of Medicine, Emory University, Atlanta, Ga.
}

\section{MATERIAL}

The subjects studied were twelve patients in whom the diagnosis of patent ductus arteriosus was made clinically. Their ages were from four to thirty-nine years (Tables I and II). The diagnosis of uncomplicated patent ductus arteriosus was made on the basis of a continuous or quasi-continuous murmur, maximal in the pulmonary valve area, the absence of cyanosis, the presence of a normal electrocardiogram, and chest $x$-rays showing normal or increased pulmonary vascular markings with slight or moderate enlargement of the left atrium and left ventricle.

\section{METHODS}

Cardiac catheterization of the right heart and pulmonary artery was done in the usual manner (6), using a single lumen catheter. Multiple blood samples were obtained from the pulmonary artery, right ventricle, right atrium, and one or both venae cavae, and analyzed in the Van Slyke apparatus. Pulmonary arterial samples for flow calculations were obtained from the distal right pulmonary artery. Following this, the catheter was quickly withdrawn, and samples were taken in rapid succession from the main pulmonary artery, right ventricle, right atrium, and venae cavae. Simultaneous pulmonary and systemic arterial pressures were obtained immediately after simultaneous pulmonary and brachial arterial blood samples. Pressures were measured by means of Hathaway strain gages and oscillograph or Sanborn transducers and Poly-Viso electrocardiograph. Systemic arterial pressure was measured through an indwelling needle in the brachial or femoral artery. In the adults, oxygen consumption was measured for flow calculations by collection of two-minute samples of expired air in Douglas bags, measurement in a Tissot spirometer, and analysis in the Haldane apparatus or in a Scholander micro gas analyzer. Simultaneous pulmonary and systemic arterial samples were taken over a one-minute period midway during the collection of expired air. In the children, oxygen consumption was calculated on the basis of surface area; these children were either sedated with one mg. of morphine per ten pounds body weight and three mg. of sodium phenobarbital per $\mathrm{Kg}$. body weight, or were anesthetized with a combination of rectal and intravenous Sodium Pentothal 18. Pulmonary flow, effective pulmonary flow, and left-toright shunt were calculated from the formulae of Bing, Vandam, and Gray (7). Left-to-right shunt through the 
ductus was calculated as the difference between total pulmonary flow and effective pulmonary flow. Pulmonary venous blood oxygen content was assumed to be 95 per cent of capacity unless the systemic arterial oxygen content exceeded this value; in those instances, pulmonary venous blood oxygen content was taken to be the same as that for systemic arterial blood. The theoretical internal diameter of the patent ductus arteriosus was calculated in accordance with the formula of Gorlin and Gorlin (5). The external diameter of the ductus was measured at operation with a caliper, either directly or with the aid of a piece of silk suture. Since the ductus was ligated rather than divided, its internal diameter was not measured. The length of the ductus arteriosus was also estimated at operation, and although this value must be considered an approximation, the theoretical internal diameter of the patent ductus arteriosus was then recalculated using a formula for the flow of a fluid through a pipe (8), based on Poiseuille's law.

\section{RESULTS}

The results are summarized in Tables I and II. All patients save one (M. C.) had normal saturation with oxygen of peripheral arterial blood. All patients had an increase in oxygen content of pulmonary arterial blood above that in the right ventricle or that in mixed venous samples from the right atrium. In two patients (A. F. and V. M.) the increase in arterial oxygen content of pulmonary arterial over right ventricular blood was of borderline significance. A significant increase in oxygenation of right ventricular blood over that in the right atrium was found in three patients (J. M., G. P., and V. M.). This was presumably due to insufficiency of the pulmonary valve (4). In the two latter patients, these samples were taken only two minutes apart. Location of the catheter tip was confirmed by pressure tracings in each instance. Disappearance of all murmur after ligation of the ductus is considered to have eliminated the possibility of ventricular septal defect as a cause of oxygenation of right ventricular blood. Patient G. P. was catheterized postoperatively and no evidence of increased oxygenation of right ventricular or pulmonary arterial blood was found. The calculated shunt through the ductus ranged from 0.8 to 17.1 liters per minute. Nine patients had mild or moderate pulmonary hypertension; three had normal pulmonary arterial pressures. Measurement of pulmonary wedge or "capillary" pressure was made in five patients. The only elevation (17 mm. mercury) was seen in a

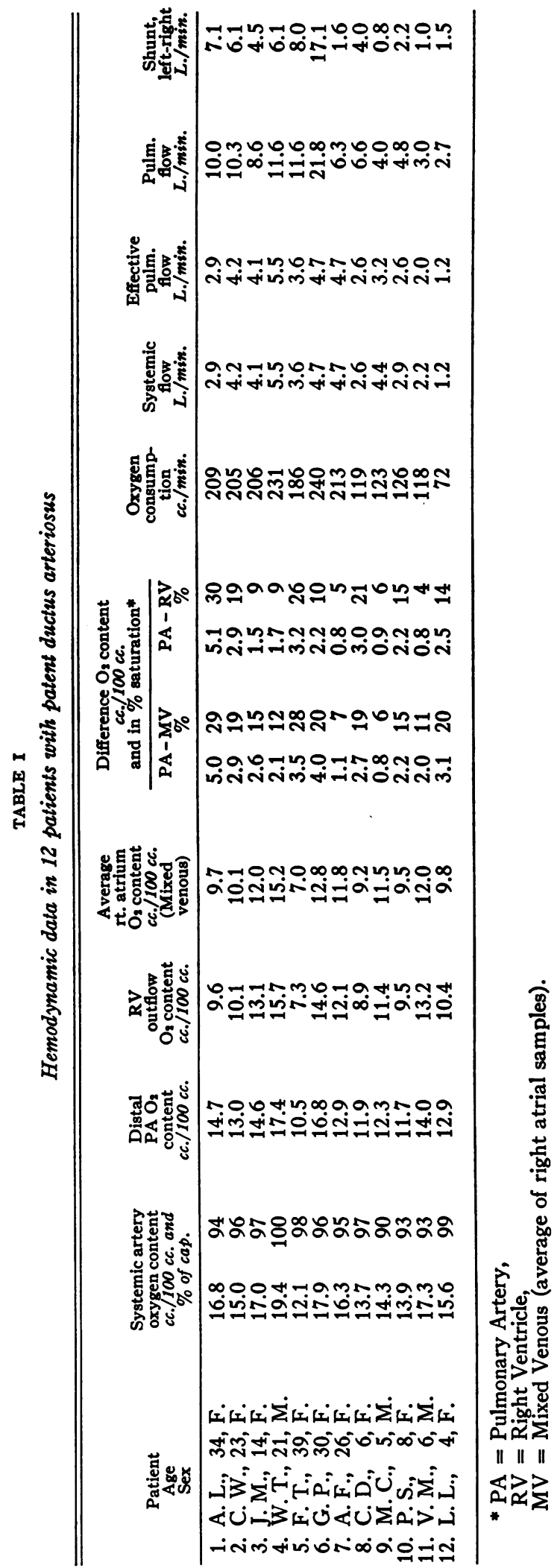


TABLE II

Pulmonary vascular pressures; calculated and observed diameter of ductus in 12 patients with patent ductus arteriosus

\begin{tabular}{|c|c|c|c|c|c|c|c|c|c|c|}
\hline $\begin{array}{c}\text { Patient } \\
\text { Age } \\
\text { Sex } \\
\end{array}$ & \multicolumn{2}{|c|}{$\begin{array}{c}\text { PA pressure* } \\
\text { sys./dias. } \\
\text { mean }\end{array}$} & $\frac{\begin{array}{c}\text { Pulm. } \\
\text { wedge } \\
\text { pressure* }\end{array}}{\overline{-}}$ & \multicolumn{2}{|c|}{$\begin{array}{c}\text { Systemic arterial } \\
\text { pressure* } \\
\text { 8ys./dias. } \\
\text { mean }\end{array}$} & \multirow{2}{*}{$\begin{array}{c}\begin{array}{c}\text { Shunt, } \\
\text { left. } \\
\text { right } \\
\text { L./min. }\end{array} \\
7.1 \\
5.7 \\
4.5 \\
5.0 \\
8.0 \\
17.1 \\
1.6 \\
3.1 \\
0.8 \\
2.2 \\
1.0 \\
1.5\end{array}$} & $\begin{array}{c}\begin{array}{c}\text { Calculated } \\
\text { internal } \\
\text { diameter } \\
\text { mmm. } \\
\text { (Orifice } \\
\text { formula) }\end{array} \\
5.8 \\
5.6\end{array}$ & $\begin{array}{c}\begin{array}{c}\text { Measured } \\
\text { external } \\
\text { diameter } \\
\text { mm. }\end{array} \\
18\end{array}$ & $\begin{array}{c}\begin{array}{c}\text { Measured } \\
\text { length } \\
\text { mm. }\end{array} \\
-\end{array}$ & $\begin{array}{c}\begin{array}{c}\text { Calculated } \\
\text { internal } \\
\text { diameter } \\
\text { (Pipe } \\
\text { formula) }\end{array} \\
--\end{array}$ \\
\hline $\begin{array}{l}\text { A. L., } 34, \text { F. } \\
\text { C. W., } 23, \text { F. } \\
\text { J. M., } 14, \text { F. } \\
\text { W. T., 21, M. } \\
\text { F. T., } 39, \text { F. } \\
\text { G. P., 30, F. } \\
\text { A. F., 26, F. } \\
\text { C. D., } \quad 6, \text { F. } \\
\text { M. C., } 5, \text { M. } \\
\text { P. S., } \quad 8, \text { F. } \\
\text { V. M., } 6, \text { M. } \\
\text { L. L., } \quad 4, \text { F. }\end{array}$ & $\begin{array}{l}\text { 二 } \\
\overline{-} \\
40 / 12 \\
26 / 16 \\
24 / 14 \\
19 / 11 \\
38 / 26 \\
27 / 8 \\
32 / 19 \\
18 / 15\end{array}$ & $\begin{array}{l}44 \\
29 \\
23 \\
21 \\
20 \\
18 \\
15 \\
33 \\
18 \\
16 \\
25 \\
16\end{array}$ & $\begin{array}{l}\frac{7}{11} \\
\frac{17}{10} \\
\frac{7}{8} \\
\frac{8}{8}\end{array}$ & $\begin{array}{c}\bar{z} \\
\bar{z} \\
149 / 62 \\
111 / 56 \\
113 / 65 \\
120 / 69 \\
100 / 57 \\
140 / 81 \\
95 / 42 \\
88 / 45\end{array}$ & $\begin{array}{r}150 \\
112 \\
- \\
93 \\
77 \\
86 \\
88 \\
64 \\
110 \\
66 \\
64\end{array}$ & & $\begin{array}{r}5.8 \\
5.6 \\
- \\
6.8 \\
10.2 \\
3.0 \\
5.0 \\
2.4 \\
3.2 \\
2.8 \\
3.2\end{array}$ & $\begin{array}{c}18 \\
9 \\
8 \\
10 \\
10 \\
14 \\
5.4 \\
10 \\
5.5 \\
5.5 \\
8.5 \\
7\end{array}$ & $\begin{array}{c}\overline{2.5} \\
6.0 \\
3.5 \\
10 \\
10 \\
6 \\
6 \\
7 \\
7 \\
8 \\
7\end{array}$ & $\begin{array}{l}\overline{3.1} \\
\overline{-} \\
\overline{4.9} \\
6.2 \\
2.9 \\
3.9 \\
2.8 \\
3.0 \\
3.2 \\
3.2\end{array}$ \\
\hline
\end{tabular}

* Pressures are expressed in mm. mercury.

woman of 39 (F. T.) with a large ductus, a large heart, and the symptom of exertional dyspnea. In ten patients, calculation of the internal diameter of the ductus was made; the values obtained ranged from 2.4 to $10.2 \mathrm{~mm}$. Observed external diameters were from 5.5 to $18 \mathrm{~mm}$. Even with allowance for variation in the thickness of the walls of the ducti, the calculated values seemed in general too small.

The regression (9) of observed external diameter on calculated internal diameter showed a significant association, $\mathrm{p}=0.02$ (Figure 1 ). Regression of external diameter on increase in percentage of oxygen saturation of pulmonary arterial over mixed venous blood (average of right atrial samples) also showed significant association, $p=0.01$ (Figure 2). Regression of external diameter of the ductus on left-to-right

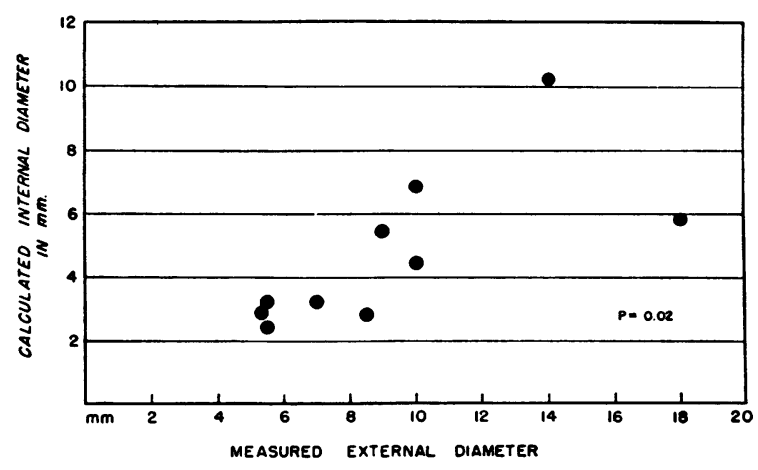

Fig. 1. Relation of Measured External Diameter to Calculated Internal Diameter in Ten Patients with Patent Ductus Arteriosus shunt showed also significant association, $\mathrm{p}=<$ 0.02 (Figure 3). An association was thus shown between the observed diameter of the ductus and each of the following: theoretical internal diameter; volume of shunt through the ductus; and increase in oxygenation of pulmonary arterial blood. The correlation was by no means linear, there being considerable scatter about the regression line. When the theoretical internal diameter of the ducti was recalculated with variation in length considered (8), a somewhat closer association was found (Figure 4$), p=0.001$, than with the orifice formula (5).

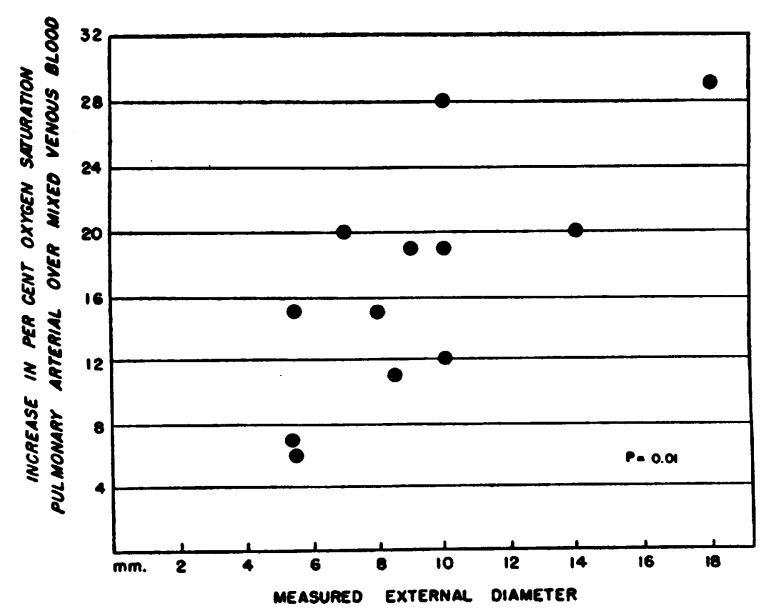

Fig. 2. Relation between Measured External DiaMeter aNd InCREase in OXygenation of Pulmonary Arterial Blood in Twelve Patients with Patent Ductus Arteriosus 


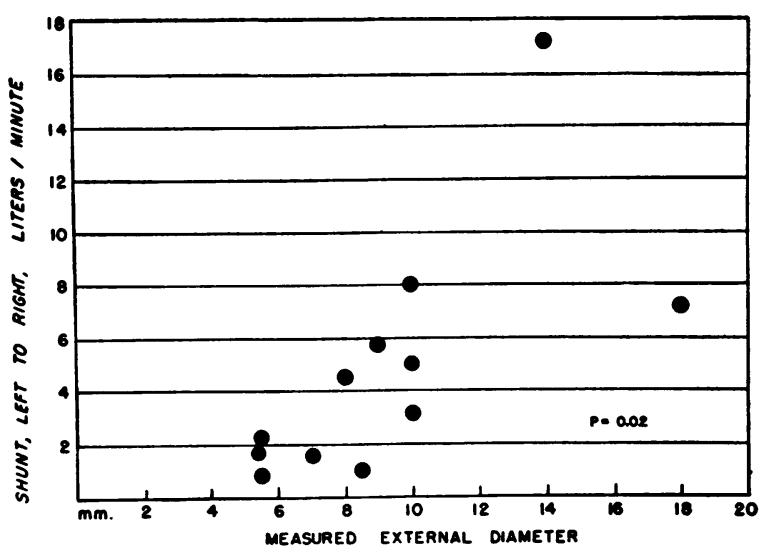

Fig. 3. Relation between Measured External Diameter and Left-to-Right Shunt in Twelve Patients with Patent Ductus Arteriosus

\section{DISCUSSION}

In 1950, Taylor, Pollack, Burchell, Clagett, and Wood (10) published a study of the correlation between flow through the ductus and its external diameter measured at operation. No significant correlation was found. However, these workers did not calculate actual volume of flow, but rather expressed flow as a percentage of left ventricular output. Theoretically, one would expect the fraction of left ventricular output passing through the ductus to decrease with increase in body size and cardiac output, assuming the cross sectional area of the ductus to remain fixed, and a constant aorta-pulmonary artery pressure gradient. These

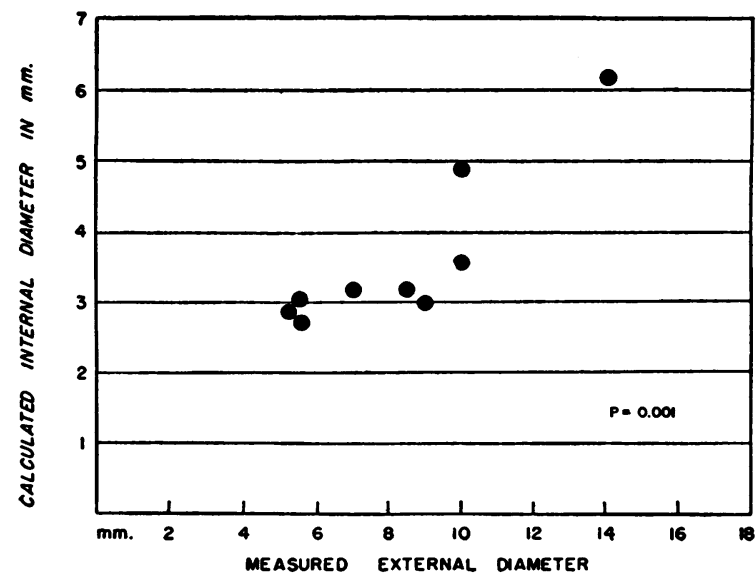

Fig. 4. Relation between Measured External Diameter and Calculated Internal Diameter in Nine Patients with Patent Ductus Arteriosus, Using the Poiseuille Equation workers did find the most constant correlation between blood flow through the ductus arteriosus and the product of the square of the radius of the ductus and the square root of the aorta-pulmonary artery pressure gradient. This corresponds to the association we found between the calculated internal diameter and the observed actual diameter.

Failure to find linear correlation between actual size of the ductus and the hemodynamic data is not surprising. There are many sources of error in such a study. The determination of the degree of increased oxygenation of pulmonary arterial blood is quite difficult, because there is poor mixing of the two blood streams when samples are taken so near the site of entrance of oxygenated blood into the pulmonary artery. To reduce this source of error, blood samples for pulmonary flow calculation were taken from the distal right pulmonary artery rather than the main pulmonary artery. Eppinger, Burwell, and Gross (1) showed that there is equal mixing of oxygenated blood in both pulmonary arteries when there is an aorticpulmonary arterial shunt into the main pulmonary artery of the dog. However, in humans, the patent ductus arteriosus may be on occasion inserted considerably to the left of the midline of the pulmonary bifurcation (1). In this event, a sample from either pulmonary artery would give an erroneous impression of the magnitude of the shunt from the aorta. The degree of oxygenation of pulmonary arterial blood is used in calculations of flow through the ductus, which value is used in turn in the calculation of the theoretical internal diameter of the ductus arteriosus. Any error in this value would cause a corresponding error in the two subsequent calculations. There is a possibility of error in the patients whose oxygen consumptions were assumed rather than measured. Variations in the steady state are a possible cause of error. In theory, one would expect the calculated flow through the ductus to be a better estimate of ductus size than the degree of increase in oxygenation of pulmonary arterial blood, since it includes the additional factor of the size of the subject. This was not seen in the data. The calculated internal diameter from the orifice formula (5) also failed to show a closer association with measured ductus size, although this determination includes the added element of pressure gradient on either side of the shunt. 
This suggests the possibility, as seems likely, that the ductus does not behave as a perfect orifice, and that there is considerable energy loss within it due to its length and possible tortuosity. The inclusion of the observed length in the formula for calculation of ductus diameter seemed to improve the association somewhat, but it is difficult to draw a conclusion from so small a sample.

Still another possible cause of difficulty in the above comparisons, relative to the measurement of ductus size, is that of variation in the thickness of the walls of the ducti, since the internal diameters were not measured. Since fluid viscosity enters into the formula for flow through short pipes (8), variations in blood viscosity are a potential source of error. Green, Lewis, Nickerson, and Heller (11) have shown that the effective viscosity of the blood decreases with increasing rates of flow, since blood is a non-homogeneous liquid. Thus variations in velocity of flow may add to the error of these calculations. Because of wave summation, systolic pressures in the femoral artery may exceed those in the aorta by as much as 20 mm. mercury (12). Thus the use of femoral arterial pressure as an estimate of aortic arch pressure in children may contribute some error.

\section{SUMMARY}

In twelve patients having a patent ductus arteriosus and subjected to ligation of the ductus at operation, a comparison was made between the observed diameter of the ductus arteriosus and certain hemodynamic data obtained by preoperative cardiac catheterization. Significant association was found between actual ductus diameter and each of the following: degree of increase in oxygenation of pulmonary arterial blood; calculated volume of blood flow through the ductus; and calculated internal diameter of the ductus. The failure of the calculated internal diameter to be a more accurate estimate of true ductus diameter than either the volume of flow through the ductus or the degree of increase in oxygenation of pulmonary arterial blood suggests that the ductus does not behave as a perfect orifice. Among the sources of error in these comparisons are diffi- culty in estimating the degree of oxygenation of pulmonary arterial blood; variations in ductus length and tortuosity; variations in steady state; variations in blood viscosity; variations in velocity of blood flow; discrepancy between femoral and aortic pressures; variations in thickness of the ductus walls.

\section{REFERENCES}

1. Eppinger, E. C., Burwell, C. S., and Gross, R. E., The effects of the patent ductus arteriosus on the circulation. J. Clin. Invest., 1941, 20, 127.

2. Dexter, L., Haynes, F. W., Burwell, C. S., Eppinger, E. C., Sosman, M. C., and Evans, J. M., Studies of congenital heart disease. III. Venous catheterization as a diagnostic aid in patent ductus arteriosus, tetralogy of Fallot, ventricular septal defect, and auricular septal defect. J. Clin. Invest., 1947, 26, 561.

3. Gross, R. E., and Longino, L. A., The patent ductus arteriosus. Observations from 412 surgically treated cases. Circulation, 1951, 3, 125.

4. Dammann, J. F., and Sell, C. G. R., Patent ductus arteriosus in the absence of a continuous murmur. Circulation, 1952, 6, 110.

5. Gorlin, R., and Gorlin, S. G., Hydraulic formula for calculation of the area of the stenotic mitral valve, other cardiac valves, and central circulatory shunts. I. Am. Heart J., 1951, 41, 1.

6. Cournand, A., and Ranges, H. A., Catheterization of the right auricle in man. Proc. Soc. Exper. Biol. \& Med., 1941, 46, 462.

7. Bing, R. J., Vandam, L. D., and Gray, F. D., Jr., Physiological studies in congenital heart disease, I, Procedures. Bull. Johns Hopkins Hosp., 1947, 80, 107.

8. Mendlowitz, M., Intravascular resistance. Am. J. Med., 1954, 16, 465.

9. Fisher, R. A., Statistical Methods for Research Workers. 11th ed., Edinburgh and London, Oliver and Boyd, 1950.

10. Taylor, B. E., Pollack, A. A., Burchell, H. B., Clagett, O. T., and Wood, E. H., Studies of the pulmonary and systemic arterial pressure in cases of patent ductus arteriosus with special reference to the effects of surgical closure. J. Clin. Invest., 1950, $29,745$.

11. Green, H. D., Lewis, R. N., Nickerson, N. D., and Heller, A. L., Blood flow, peripheral resistance and vascular tonus, with observations on the relationship between blood flow and cutaneous temperature. Am. J. Physiol., 1944, 141, 518.

12. Wiggers, C. J., Circulatory Dynamics; Physiologic Studies. New York, Grune and Stratton, 1952. 